\title{
Letramento crítico, ética e ensino de língua inglesa no século XXI: por um diálogo entre culturas
}

\section{Critical literacy, ethics and English language teaching in the $21^{\text {st }}$ century: for a dialogue among cultures}

William Mineo Tagata*

Universidade Federal de Uberlândia (UFU)

Uberlândia, Minas Gerais / Brasil

\begin{abstract}
RESUMO: Este artigo se propõe a discutir a relação entre letramento crítico, ética e ensino de língua inglesa. Apresenta argumentos a favor do ensino de inglês em uma perspectiva de letramento crítico, de modo a formar sujeitos éticos e ajudar a promover relações sociais mais justas. Inicia com uma consideração sobre a relevância do conceito de ética para os estudos sobre linguagem realizados na área da Linguística Aplicada. Em seguida, discorre sobre a noção de diálogo entre culturas. Passa então a uma análise da contribuição de estudos de letramento crítico feitos por autores preocupados com a questão de uma ética contemporânea, possibilitada pela tradução cultural. Por fim, sugere que o ensino de inglês segundo o letramento crítico deve desenvolver o conhecimento procedimental dos alunos.
\end{abstract}

PALAVRAS-CHAVE: Letramento crítico; ética; tradução intercultural; ensino e aprendizado de inglês.

ABSTRACT: This paper aims to discuss the relationship among critical
literacy, ethics and English language teaching. It presents arguments in favour
of teaching English in a critical literacy perspective in order to form ethical
subjects and help promote just social relations. It begins with an examination
of the relevance of ethics to the studies on language in the field of Applied
Linguistics. Next, it discusses the idea of dialogue among cultures (JULLIEN,
2010). It then goes on to an analysis of the contribution of critical literacy
studies carried out by authors concerned with the problem of a contemporary
ethics, made possible by cultural translation. Last, it suggests that teaching
English according to critical literacy should seek to develop students' procedural
knowledge (CANAGARAJAH, 2014). KEYWORDS: Critical literacy; ethics; intercultural translation; teaching and learning English.

*wtagata@gmail.com 


\section{Introdução}

Recentes acontecimentos no cenário político têm provocado discussões acaloradas em diversos setores da sociedade brasileira. Dentre os temas que pontuam boa parte das conversas informais, postagens nas redes sociais ou notícias de jornais, figuram, entre outros assuntos, a corrupção em diversas esferas da administração pública e o papel da mídia na cobertura dos escândalos. Questiona-se, por exemplo, se um deputado faltou com decoro parlamentar, ou se um juiz agiu corretamente ao divulgar informações sigilosas à imprensa. Em muitos casos, o que está em discussão é a questão da ética - ou a falta dela.

De fato, nunca se falou tanto de ética quanto atualmente, não apenas no âmbito da política, mas também no campo das ações cotidianas. Tida como um dos temas mais tradicionais no estudo da filosofia, a ética se aplica diretamente a nossa experiência do dia a dia. Segundo Marcondes (2007), uma reflexão sobre os valores éticos que permeiam nossas ações pode nos levar a superar os condicionamentos do contexto em que nos encontramos e desenvolver uma postura crítica, caracterizada por um distanciamento em relação aos padrões e modos de pensamento a que nos acostumamos. Pensar de formas diferentes, pensar criticamente sobre o próprio pensamento, de forma a não legitimar apenas o que já sabemos: esse seria o propósito e até mesmo a natureza de toda atividade filosófica, de acordo com Foucault (2006). A meu ver, assim como o fazer filosófico, o ensino de línguas em geral e o de inglês, em particular, pode estimular o mesmo tipo de reflexão crítica sobre a língua no contexto global atual, particularmente no sentido de contribuir para uma investigação de seu papel na disseminação da ideologia neoliberal da globalização, e também para a formação de uma aliança anti-hegemônica, como defendido por Moita Lopes (2008). A meu ver, essa reflexão pode se dar como parte de uma proposta de ensino de inglês segundo o letramento crítico, como veremos adiante.

Neste artigo, ${ }^{1}$ resultado de minha pesquisa de pós-doutorado em uma universidade brasileira, investigo o que o ensino e o aprendizado de

\footnotetext{
${ }^{1}$ Minha pesquisa de pós-doutorado, concluída em 2016, teve por objetivo investigar a possibilidade de ensino de inglês em uma perspectiva de letramento crítico, de modo a contribuir para o desenvolvimento de uma ética contemporânea. Tratou-se, portanto, de um conjunto de reflexões teóricas, resultante de uma aproximação entre Filosofia e Linguística Aplicada. De forma semelhante, neste artigo não pretendo promover uma articulação entre teoria e prática ou apresentar propostas de ensino nessa perspectiva.
} 
inglês em uma perspectiva de letramento crítico têm a contribuir para o desenvolvimento de uma ética em um mundo marcado por intensas trocas interculturais, de forma a promover a preservação das diversidades social, cultural, linguística e ambiental do mundo. Inicio com uma consideração sobre a relevância do conceito de ética para os estudos sobre linguagem, sobretudo os realizados na área da Linguística Aplicada. Vale ressaltar que meu objetivo neste artigo não é o de elaborar uma proposta de ensino de inglês pautada nos estudos de letramento crítico, mas apenas empreender uma discussão teórica sobre a importância da questão da ética em tal proposta. Espero, dessa forma, contribuir para a inserção do tema nos debates e estudos em Linguística Aplicada, comprometida com questões de extrema pertinência para nosso cotidiano social e político.

\section{Linguagem e ética}

Não é de se esperar que um linguista se debruce sobre questões éticas relativas a sua pesquisa, afirma Rajagopalan (2013). Linguista de formação, o autor reconhece que, por se ocuparem de um fenômeno aparentemente "natural" - a linguagem -, muitos de seus colegas automaticamente se eximem da obrigação de levar em conta os aspectos éticos de sua pesquisa, principalmente se ela consistir na elaboração de teorias sobre a linguagem. No entanto, o autor assevera que, por mais neutra ou imparcial que uma teoria possa parecer, sempre estará político-ideologicamente comprometida. A incapacidade dos linguistas de reconhecerem essa motivação políticoideológica se deve, de acordo com o autor, à tendência de associar ética ao campo da prática, em que nos é possível exercer uma liberdade de escolha. Para Rajagopalan (2013, p. 22), porém, é preciso ter em mente que "a atividade de formular teorias é algo que se dá como parte de uma prática social", desempenhada por pesquisadores que não se encontram em um vácuo social e que, portanto, não conseguem se despir de seus anseios e interesses pessoais ao elaborar teorias. Por isso, é mister abandonar o mito da neutralidade do linguista e questionar quais as considerações éticas e políticas por trás de uma teoria linguística. Em última instância, segundo o autor, isso equivale a uma reflexão crítica sobre as condições em que ocorre a construção de conhecimento:

Estamos procurando entender, entre outras coisas, quais os recortes que o novo saber efetua, e ao fazer isso, quais exclusões ele legitima. A preocupação principal aqui é dar largada a uma discussão acerca 
dessas questões com a esperança de que ela traga subsídios para uma maior conscientização do aspecto ético das nossas práticas teóricas. (RAJAGOPALAN, 2013, p. 22).

A consciência da dimensão ética de nossas pesquisas sobre a linguagem é de suma importância para a elaboração de teorias produzidas no âmbito da Linguística Aplicada, segundo autores como Fabrício (2008) e Moita Lopes (2008), entre outros. Em um mundo marcado pelo questionamento de dicotomias e valores tradicionais e pelo surgimento de novos posicionamentos sociais, políticos e culturais, Fabrício (2008, p. 46) propõe a seguinte questão de natureza epistemológica: "como a ideia de trânsito permanente está afetando as teorizações contemporâneas acerca de nossas práticas discursivas?". Ancorada na visão de linguagem como prática social e, portanto, política e ideologicamente comprometida, a autora questiona como é possível produzir conhecimentos sobre as práticas discursivas contemporâneas em "uma perspectiva da trama movente" (FABRÍCIO, 2008, p. 59). Trata-se de uma tarefa que deve se pautar por uma agenda política, uma agenda transformadora e também uma agenda ética, baseada na suposição de que "nossas práticas discursivas envolvem escolhas que têm impactos diferenciados no mundo social e nele interferem de formas variadas" (FABRÍCIO, 2008, p. 49). Porém, o problema daí decorrente é o de como falar de ética sem generalizar o conceito, caindo em abstrações ou essencialismos baseados em parâmetros fixos do que pode ou não ser considerado ético. A saída encontrada pela autora está em uma concepção de ética situada na intersecção entre discurso e ação, de modo a avaliarmos nossas ações com base não em valores universais, mas em "valores democraticamente definidos na esfera pública e no diálogo aberto" (FABRÍCIO, 2008, p. 62). Segundo a autora,

Podemos fazer isso através da expressão das razões pelas quais agimos, que, por sua vez, só podem ser justificadas inseridas em determinado sistema e em seus próprios padrões de justificação, ao verificarmos, em interlocução coletiva, os ganhos epistêmicos dos padrões sociais de determinadas ações. (FABRÍCIO, 2008, p. 62)

São "valores democraticamente definidos na esfera pública e no diálogo aberto" que devem orientar o exame do modo como agimos e das razões por que agimos dessa forma. Definidos na esfera pública e com base do diálogo, esses valores não podem ser estabelecidos a priori, fora do contexto a se aplicam - daí sua parcialidade ou incompletude. (Co) 
construímos nossos valores dialogicamente, na interação com o Outro, em um espaço de "interlocução coletiva" em que se medem nossas ações a partir de seu "ganho epistêmico", segundo a autora. Por isso, uma tendência entre os pesquisadores é no sentido de trabalhar para uma Linguística Aplicada responsável, solidária e aberta a configurações epistemológicas diferentes.

"Como pensar novas formas de produzir conhecimento com base em outros olhares e colaborar na reinvenção da vida social?”, indaga Moita Lopes (2008, p. 94), a partir da constatação de que "uma transformação profunda nos modos de conhecer deveria estar relacionada [...] com uma transformação profunda nos modos de organizar a sociedade" (SANTOS, 2001 apud MOITA LOPES, 2008, p. 91). O autor parte do princípio de que embutido em qualquer sistema de conhecimento encontra-se um ideal de sociedade, e que as mudanças sociais e culturais de nosso tempo requerem modos alternativos de construção de conhecimento, de forma a combater os valores hegemônicos de um capitalismo neoliberal, responsável por perpetuar tantas desigualdades e injustiças sociais, como aquelas que promovem a riqueza econômica e a ampla difusão dos conhecimentos dos países ricos do hemisfério norte, em detrimento das "vozes do Sul" (SANTOS, 2001 apud MOITA LOPES, 2008, p. 94) - daí a necessidade de uma Linguística Aplicada transdisciplinar ou até mesmo indisciplinar é alheia à separação entre teoria e prática. Uma Linguística Aplicada dessa natureza, segundo o autor, reconheceria a centralidade da ética na vida social e na pesquisa, de modo a refutar práticas sociais e posturas epistemológicas que, de alguma forma, podem marginalizar, excluir ou infligir sofrimento a determinados grupos sociais. Esse princípio ético justifica a construção de saberes com base no respeito à diferença, como parte de "um processo de renarração ou redescrição da vida social” (SANTOS, 2001 apudMOITA LOPES, 2008, p. 90) em que a alteridade oriunda de outros modos de vida e formas de racionalidade pode ampliar nossa imaginação epistemológica:

A possibilidade de experimentar a vida de outros para além da vida local é talvez a grande contribuição da vida contemporânea, ao nos tirar de nosso mundo e de nossas certezas que apagam quem é diferente de nós e não nos possibilitam viver outras formas de sociabilidade. (SANTOS, 2001 apud MOITA LOPES, 2008, p. 92).

O encontro com a alteridade situada "além da vida local" pode constituir uma oportunidade de pensar diferentemente e de rever nosso sistema de valores, promovendo uma reflexão crítica de como nossas 
crenças são produto de esquemas conceituais contingentes, situados numa configuração social, histórica e cultural específica. Segundo Pennycook (2001), trata-se de uma proposta de pedagogia em que a sala de aula não constitui um simples reflexo da sociedade, nem se encontra a salvo de sua influência direta, mas é um espaço de múltiplas relações e imbricações entre o individual e o coletivo, onde somos levados a refletir sobre como nossos pequenos gestos cotidianos contribuem para manter, legitimar ou desafiar uma configuração de poder. Nessa perspectiva, Pennycook (2001, p. 137, tradução nossa) sugere conceber ética não como um código fixo de regras, mas como "uma forma contingente de pensar e agir que está sempre implicada em relações sociais, culturais e políticas". ${ }^{2}$ Essa maneira particular de pensar e agir implica atitudes responsáveis perante o outro, de modo que as diversidades ontológica e epistemológica do mundo possam ser respeitadas. É somente desse modo que podemos atender à "demanda ética de imaginar de outras formas" (PENNYCOOK, 2001, p. 138, tradução nossa). ${ }^{3}$

Haja vista a importância de aspectos éticos e políticos em pesquisas sobre linguagem, a Linguística Aplicada não pode se furtar a investigar questões como os efeitos da inclusão ou exclusão do inglês no currículo escolar, o papel dos professores de inglês na difusão da língua e as consequências políticas, econômicas e culturais dessa disseminação - como a diminuição do número de falantes das línguas locais. Trata-se de um conjunto de questões que não se limitam à Linguística Aplicada, tendo sido objeto de investigação de filósofos como François Jullien.

\section{Por um diálogo e uma tradução entre culturas}

Para Jullien (2010), a tradução é a única ética possível do mundo global contemporâneo. Tradução, para o filósofo, ultrapassa o sentido puramente linguístico e implica um esforço recíproco, um processo laborioso em que duas ou mais línguas ou culturas têm que se fazer entender, por meio de um compromisso mútuo de autorreflexão, a partir do qual devem examinar e possivelmente reelaborar seus pressupostos, para assim se fazer inteligíveis.

\footnotetext{
${ }^{2}$ No original: "the need to understand ethics not as part of a fixed moral code that guides the behavior of the individual but rather as part of a contingent way of thinking and acting that is always in relation to social, cultural and political relations".

${ }^{3}$ No original: "the ethical demand to imagine otherwise".
} 
De um lado, Jullien associa a noção de inteligibilidade à palavra grega logos, em "dia-logo"; de outro, reconhece em dia a ideia de defasagem entre culturas, a distância entre elas que as mantém em constante tensão. Assim concebido por Jullian (2010, p. 200), o "dia-logo" é "uma estrutura eficiente - operante - que obriga de facto a reelaborar suas próprias concepções para entrar em comunicação e, logo, também a se refletir". Enquanto "plena exigência a um e a outro de seus componentes", esse "dia-logo" necessita que cada cultura torne inteligíveis em sua própria língua os valores de outra cultura, refletindo-se a partir deles; um "dia-logo" não como um meio termo feito de concessões - visto que, para o filósofo, "valores são inegociáveis" (JULLIAN, 2010, p. 178), não coincidem e não se pode abrir mão deles -, mas como a busca pela compreensão, em que cada um se abra igualmente à visão de mundo do outro, mediante sua inteligência. Não sejamos ingênuos, adverte Jullien, a ponto de idealizarmos um diálogo neutro, entre iguais, conforme preconizado por um "humanismo frouxo" que acaba por fazer vista grossa às relações desiguais de poder. Para dialogar de facto, sugere o filósofo, "cada um deve, imperativamente, descerrar sua posição, colocá-la em tensão e instaurá-la em relação” (JULLIAN, 2010, p. 200). Em outras palavras, trata-se de um processo em que os participantes são levados a explicitar seus valores e posicionamentos, examinando-os criticamente em sua relação com os valores de outrem, e, provavelmente, a reelaborar seus pressupostos para poderem se comunicar.

Convém ressaltar a importância dada a Jullien (2010) à defasagem - e não diferença - entre culturas, pois falar em diferença entre culturas implica distinção, enquanto defasagem pressupõe distanciamento, e por distanciar, "põe em tensão" aquilo que separou. Por fim, a diferença é o oposto de idêntico, ao passo que a defasagem se opõe ao esperado, ao já conhecido, e assim "descobre um outro possível: seu ponto de vista atenta, ainda que de maneira implícita, contra o normativo" (JULLIAN, 2010, p. 185). Ou seja, em contraste com a diferença, entendida numa perspectiva de descrição, a defasagem pode ser vista como prospeç̧ão, pois "explora até onde outros caminhos podem ser trilhados". Esse trabalho de prospecção das culturas deve começar pela língua, sugere Jullien. Por isso, deve-se falar em defasagem das línguas - e não diferença:

Falar da diferença das línguas, especialmente, nos limitaria a desenvolver esse plural inventariando a multiplicidade das estruturas e das formas; enquanto tratar da defasagem das línguas leva a sondar até onde podem ir 
essas singularidades e quais ramificações elas abrem no pensamento. (JULLIAN, 2010, p. 185).

O filósofo defende ainda a necessidade de estimular o "trabalho inventivo do pensamento" (JULLIAN, 2010, p. 185), com vistas a instaurar-nos todos como "sujeitos possiveis, como sujeitos culturais", tendo oportunidades de "autopromoção e de um futuro inventivo". Eis a grande vantagem de uma reflexão sobre a defasagem entre as culturas/línguas, baseada em movimentos contínuos de diferenciação e de superação: o desafio de pensar inventivamente e instaurar cada um de nós como "sujeitos culturais possiveis", incluindo aí a possibilidade de sujeitos à margem do conceito universal da razão ocidental, não assujeitados ao reinado do uniforme.

A reflexão de Jullien sobre a defasagem das culturas começa a partir da língua. O filósofo traz alguns exemplos oriundos da língua chinesa, como o da palavra "paisagem", ou "shan-shui" - literalmente, "montanha(s)-água(s)" ou "montanha(s)-rio(s)", simbolizando oposições como "vertical $\times$ horizontal", "maciço $\times$ fluido", e "imóvel $\times$ movente", entre outras. São oposições que colocam o mundo em permanente tensão, sujeito a trocas constantes; assim, ao invés de se referir a um recorte específico no espaço, feito por um observador cuja visão lhe permite apreender uma porção limitada do mundo, "a "paisagem" chinesa opera a globalidade funcional de elementos, ou antes, de fatores (vetores), em interação” (JULLIAN, 2010, p. 187). Em outras palavras, destaca-se, na "paisagem" chinesa, o signo da interação e do fluxo incessante entre elementos por nós considerados separados ou distintos.

A defasagem que se abre entre culturas e línguas constitui, para Jullien (2010, p. 190), uma estratégia de resistência contra a "perda, por esterilização globalizada, de formas culturais e coerências de pensamento que poderiam contribuir para o desenvolvimento, não como museu, mas como porvir, do cultural e do pensável"; resistência, portanto, contra a discreta imposição do "uniforme", que a globalização estende a todas as áreas do mundo e faz passar por "universal"; resistência, ainda, que visa a estimular o exercício inventivo do pensamento - buscando formas alternativas e imprevisíveis de pensamento, fora da lógica hegemônica do ocidente - e ao reconhecimento e validação de outros sujeitos culturais possíveis. Por isso, o conceito de defasagem é especialmente poderoso, pois 
ao nos levar a sondar até onde podem ir as divergências, a avaliar a distância que se abre entre elas, ele desdobra o cultural e o pensável no seu limite. Mas também, em sentido inverso, dessa dispersão oferecida nos faz voltar às suas escolhas implícitas, no início de separação e até na lógica do que seremos efetivamente levados a representar a partir disso, de ambos os lados, num pé de igualdade e como outras tantas alternativas para o pensamento. (JULLIAN, 2010, p. 191).

O conceito de defasagem opera, portanto, um duplo movimento. Primeiro, sugere a necessidade de abertura epistemológica a diferentes saberes, muitas vezes ignorados por um "pensamento ortopédico", que Santos (2010) acusa de excluir boa parte das experiências sociais disponíveis ou possíveis no mundo. Segundo, em um movimento inverso, o conceito de defasagem nos convida a questionar as bases de nosso próprio pensamento, que nos leva a formular determinadas representações da realidade, em detrimento de outras. Esse duplo movimento, a meu ver, também está na base das reflexões sobre letramento crítico desenvolvidas por autores como Andreotti (2014), Green, Lankshear e Snyder (2000), Janks (2012) e Souza (2011a, 2011b), como veremos a seguir.

\section{Letramento crítico e ensino de línguas}

Como conceber letramento em uma investigação sobre os aspectos éticos do ensino de línguas? É preciso adotar uma visão de letramento que privilegie sua natureza social e leve em conta a possibilidade de apropriarse da linguagem e de transformá-la. Essa visão crítica de letramento é compartilhada por Green, Lankshear e Snyder (2000, p. 31, tradução nossa):

A dimensão "crítica" envolve a consciência de que todas as práticas sociais, e, portanto, todos os letramentos, são socialmente construídas e "seletivas": elas incluem algumas representações e classificações valores, propósitos, regras, padrões, perspectivas - e excluem outras. Para participar efetiva e produtivamente de qualquer prática letrada, as pessoas precisam ser nela socializadas. Mas se os indivíduos são socializados em um letramento sem perceberem que ele é socialmente construído e seletivo, e que também pode-se atuar sobre ele e transformá-lo, eles não podem desempenhar um papel ativo em mudá-lo. A dimensão crítica do letramento é o fundamento para garantir que os indivíduos não sejam apenas capazes de participar de um determinado letramento e nele 
produzir sentidos, mas também que, de várias formas, eles são capazes de transformá-lo e ativamente produzi-lo. ${ }^{4}$

Vemos, portanto, como o letramento crítico objetiva conscientizar o aluno de seu papel ativo na construção e reconstrução de sentidos, de modo que eles reflitam seus propósitos e perspectivas. De certa forma, a perspectiva crítica acaba por levar o aluno para "além do pensamento ingênuo e do senso comum", de acordo com Souza (2011a), pois o aluno se vê compelido a refletir sobre suas próprias crenças, valores, convicções e maneiras de ler o mundo, e perceber que esses valores, opiniões e crenças longe de serem "naturais" - se originam na comunidade onde vivemos, nas famílias e nos grupos sociais por onde circulamos:

Aqui, no letramento crítico, precisamos assumir a responsabilidade das nossas leituras e não culpar o autor do texto pela sua escritura; precisamos perceber que o significado de um texto é uma inter-relação entre a escrita e a leitura. Nós estamos nos conscientizando sobre como nós interpretamos o texto. [...] Enfocar aquilo que o aluno acha que é "natural" fazer, levar o aluno a repensar o que é natural para ele e refletir sobre isso. Perceber como aquilo que é natural para ele pode conter preconceitos que podem afetar o outro, gerar preconceito contra pessoas diferentes. E, portanto levar o aluno, o aprendiz, a reformular seu saber ingênuo. Então letramento crítico é ir além do senso comum, fazer o aluno refletir sobre aquilo que ele pensa que é natural e verdadeiro. Levar o aluno a refletir sobre a história, sobre o contexto de seus saberes, seu senso comum. Levar o aluno a perceber que para alguém que vive em outro contexto a verdade pode ser diferente. (SOUZA, 2011a, p. 295).

A importância do contexto de leitura e interpretação é assinalada por todos os estudiosos de letramento crítico, preocupados com as relações entre ética e linguagem. Para Souza (2011a), a ética se baseia na compreensão de

\footnotetext{
${ }^{4}$ No original: "The 'critical' dimension involves awareness that all social practices, and hence all literacies, are socially constructed and 'selective': they include some representations and classifications - values, purposes, rules, standards, perspectives - and exclude others. To participate effectively and productively in any literate practice, people must be socialised into it. But if individuals are socialised into a literacy without realising that it is socially constructed and selective, and also that it can be acted on and transformed, they cannot play an active role in changing it. The critical dimension of literacy is the basis for ensuring that individuals are not merely able to participate in an existing literacy and make meanings within it, but also that, in various ways, they are able to transform and actively produce it".
} 
que "a verdade pode ser diferente" para quem vive em contextos diversos. A partir da ideia de verdade como uma - entre outras tantas-interpretação produzida em um contexto sócio-histórico específico, Souza (2011a) sugere que somos éticos não só porque estamos cientes da diversidade de interpretações provenientes de diferentes contextos, mas principalmente por causa de nossa capacidade de ouvir, de fato, o outro. Esse ouvir, como veremos adiante, é também ouvir a si mesmo, submetendo nossas próprias interpretações a um escrutínio rigoroso. Donde resulta a ética, e com ela a percepção da impossibilidade de eliminação da diferença e da necessidade de negociar e interagir pacificamente com ela (SOUZA, 2011b). De acordo com o autor, o ensino de línguas segundo o letramento crítico pode desenvolver essa percepção por parte de professores e alunos.

Assim como Souza (2011a, 2011b), Janks (2012) nos convida a refletir sobre a necessidade de uma ética de justiça social como parâmetro na avaliação dos efeitos sociais da linguagem. Essa é, para Janks, a característica principal do letramento crítico como concebido por ela. A criticidade, segundo a autora, reside na capacidade de reconhecer que os pontos de vista ou interesses do autor de um texto não coincidem necessariamente com os do leitor, ou de leitores situados em contextos sociais e culturais diferentes, sendo-lhes possível reconstrui-lo, atribuindo-lhe seus próprios sentidos. Nesse aspecto, Janks parece corroborar a ideia de Souza (2011a), apresentada anteriormente, de que "o significado de um texto é uma inter-relação entre a escrita e a leitura", sendo-nos necessário "assumir a responsabilidade das nossas leituras" e refletir sobre nosso processo interpretativo. Para Janks (2012, p. 159, tradução nossa), portanto, o letramento crítico consiste na "habilidade de compreender que os discursos nos produzem, falam através de nós e podem, entretanto, ser desafiados e mudados". ${ }^{5}$ Nesse sentido, a autora também compartilha da ideia, expressada por Green, Lankshear e Snyder, de que, embora sejamos todos socializados através de um conjunto de práticas letradas, é-nos possível agir para transformá-las. ${ }^{6}$

\footnotetext{
${ }^{5}$ No original: "the ability to understand that discourses produce us, speak through us and can nevertheless be challenged and changed".

${ }^{6}$ Posição semelhante também é defendida por Cope e Kalantzis (2012), para quem o letramento crítico valoriza as vozes e experiências que professores e alunos trazem para a escola, reconhecendo-os enquanto responsáveis por seu processo de aprendizagem, e capazes de reverter as condições sociais, políticas e econômicas desfavoráveis em que se encontram.
} 
Penso que os estudos de Janks, Souza e Green, Lankshear e Snyder podem contribuir na constituição de uma base teórico-políticoepistemológica para o planejamento e a execução de práticas de letramento envolvendo o ensino e o aprendizado da língua inglesa, tanto em um micronível - por exemplo, na elaboração de planos e materiais destinados a promover uma conscientização da heterogeneidade linguística e cultural de países de língua inglesa, e de novas estratégias de apropriação do inglês quanto em um macronível - por exemplo, no desenvolvimento de atitudes éticas que contribuam para a preservação das diversidades linguística, cultural, epistemológica e ambiental do mundo. Em outras palavras, interessa-me a reflexão sobre como os estudos de letramento crítico podem oferecer novos rumos e possibilidades para o ensino de língua inglesa, ao mesmo tempo desencadeando uma revisão do sentido da ética no mundo atual. Como justificar a importância da ética em uma proposta de letramento crítico? Como o ensino e o aprendizado de inglês em uma perspectiva de letramento crítico podem contribuir para a formação de sujeitos críticos dispostos a relacionar-se eticamente entre si e com outras culturas? E de que modo pode engajar alunos e de professores de inglês em uma reflexão crítica sobre o papel da língua na atual conjuntura política, cultural e econômica, e sobre as possibilidades de construção de um discurso de resistência à globalização neoliberal, a favor de uma globalização mais justa?

Criticidade, aqui, significa assumir a responsabilidade por nossas leituras e reconhecer nosso papel na construção dos saberes e dos sentidos que atribuímos aos textos, nunca naturais, mas necessariamente fabricados, e relativos a um contexto específico. Para Souza (2011a), criticidade e ética estão estreitamente relacionadas, pois sugerem a necessidade de "ler se lendo", isto é, posicionar-se criticamente em relação ao modo como atribuímos sentido ao que lemos (baseado em nossas leituras anteriores e experiências de vida), que pode ser diferente das leituras e interpretações de alguém situado em outro contexto. Aqui Souza recupera o trabalho de Freire (1987), para quem a leitura do mundo necessariamente precede a leitura da palavra, e criticidade envolve tomada de consciência sobre a relação entre palavra e mundo. Freire inspira, assim, uma concepção de letramento enquanto leitura do mundo - ou palavramundo -, que atribui aos contextos e bagagem de vida dos alunos um papel central no planejamento e execução de ações pedagógicas. Isso quer dizer que, na sala de aula freireana, importa mais a valorização crítica e o questionamento das experiências de vida dos 
alunos do que um currículo baseado em um conjunto pré-estabelecido de conteúdos a serem transmitidos a alunos situados em diferentes contextos. Afinal de contas, segundo Freire (1987), nossa leitura do mundo precede a leitura da palavra, e ler uma palavra é sempre ter acesso a uma versão específica do mundo.

Freire influenciou um número significativo de pesquisadores de letramento crítico identificados com questões pós-coloniais, como Andreotti (2014). ${ }^{7}$ Para a autora, a formação de professores em uma perspectiva de letramento crítico ou transnacional deve promover a contextualização dos saberes e práticas culturais como parte do desenvolvimento de uma autorreflexividade, entendida como "a prática de relacionar suposições individuais a 'histórias' coletivas socialmente, culturalmente e historicamente situadas, com pressupostos ontológicos e epistemológicos específicos que definem o que é real, ideal e cognoscível" (ANDREOT'TI, 2014, p. 36, tradução nossa). ${ }^{8}$

Segundo ela, a autorreflexividade equivale, portanto, à constatação de que o sujeito não é a origem primordial dos significados da linguagem e da cultura, e que suas escolhas nunca são completamente livres ou neutras, porém condicionadas pelo contexto social, histórico e cultural em que está inserido. São as histórias coletivas aí circulantes que determinam o que é real, possível e cognoscível. Para Andreotti, a autorreflexividade também pressupõe o questionamento da transparência do sujeito e de sua plena consciência da relação entre ações, pensamentos e palavras. Afinal de contas, o que está em jogo é a constituição complexa das subjetividades, da coimplicação entre poder e conhecimento, e do papel exercido pelo inconsciente em nossa relação com o mundo. A autora questiona a crença na existência de significados e conhecimentos objetivos, característica da racionalidade positivista subjacente à pesquisa científica tradicional,

\footnotetext{
${ }^{7}$ Interessa-nos, aqui, destacar a influência de Freire nos trabalhos sobre letramento crítico realizados por teóricos pós-coloniais como Souza e Andreotti. Entretanto, é preciso apontar também a existência de divergências quanto à relevância de Freire para uma reflexão sobre as relações entre ética e linguagem. Essas tensões aparecem, por exemplo, no trabalho de autores pós-modernos que se opõem a uma visão humanista e universalista de ética, que atribuem à obra de Freire.

${ }^{8}$ No original: "the practice of tracing individual assumptions to collective socially, culturally and historically situated "stories" with specific ontological and epistemological assumptions that define what is real, ideal and knowable".
} 
que acabou influenciando também as pesquisas nas ciências humanas e desvalorizando outras possibilidades de significação, ignoradas pela globalização neoliberal. Para a autora, uma educação pautada pela ética em tempos de globalização requer uma análise cuidadosa da imbricação das forças sociais, culturais, econômicas e históricas que afetam pessoas e lugares. $\mathrm{Na}$ falta dessa análise, a educação tende a reproduzir as relações assimétricas entre povos dominantes e marginalizados, deixando de fora as questões de responsabilidade social e diversidade cultural.

Andreotti (2014) sugere que somente uma educação baseada em um projeto de letramento crítico pode dar conta de tal análise. Entendido como um conjunto de práticas educacionais que enfatizam as relações entre linguagem, conhecimento, poder e subjetividades, o letramento crítico, segundo a autora, promove a problematização de grandes narrativas (como, por exemplo, "desenvolvimento", "identidade", "progresso" ou "conhecimento"), ao mesmo tempo que chama atenção para a limitação de nossos conhecimentos e interpretações de mundo - sempre parciais e contingentes - e para a existência de múltiplas perspectivas, assim como identidades e linguagens híbridas. Para a autora, "é importante reconhecer nossa cegueira constitutiva em relação a outras formas de ver, conhecer e de estar no mundo que não se enquadram nos quadros de referência a que nos acostumamos" (ANDREOTTI, 2014, p. 45, tradução nossa).?

De acordo com Andreotti, o que somos capazes de ver nos cega para algumas coisas; de forma semelhante, o que nos é possível conhecer nos impossibilita de conhecer outras coisas. Em outras palavras, o que a autora aponta é, em última instância, a limitação da própria linguagem uma questão complexa que o letramento crítico pode problematizar. Para compensar nossa "cegueira constitutiva", sugere Andreotti, em consonância com Souza e Freire, é preciso empreender uma autoavaliação crítica de nossas próprias leituras do mundo, de modo a analisar como nossos conhecimentos e interpretações dificultam a compreensão e a aceitação de outros saberes e modos de vida, e, assim, respeitar e valorizar a diversidade epistemológica do mundo, também defendida por Santos (2010). Nisso reside a preocupação com a ética subjacente às reflexões desses autores, da

\footnotetext{
${ }^{9}$ No original: "it is important to acknowledge our constitutive blindness to other forms of seeing, knowing and being in the world that do not fit what we can recognize through the frames of reference we have become used to".
} 
qual compartilho, e que pode nos levar à questão formulada por Andreotti (2014): como superar as limitações de nossos conhecimentos atuais, a fim de abordar a complexidade, a incerteza, a pluralidade e a desigualdade no mundo contemporâneo? Podemos encontrar uma resposta a essa questão nas reflexões de Jullien (2010), para quem, como vimos anteriormente, essas limitações podem ser enfrentadas através do diálogo entre culturas.

\section{Letramento crítico, ética e o conhecimento procedimental no ensino de inglês como língua fraca}

Parece-me oportuno apontar a semelhança entre o movimento de defasagem de línguas e culturas (JULLIEN, 2010) e os estudos de letramento crítico aqui mencionados. A meu ver, o letramento crítico coloca conceitos, línguas e culturas em defasagem, ainda mais em situações de ensino e aprendizagem de línguas estrangeiras. O contato com a língua chinesa, como exemplificado pelo autor, pode estimular um processo reflexivo marcado por um "ouvir-se ouvindo", capaz de suscitar questões como: como e por que sou levado a conceber e designar "paisagem" como tal? Que concepções de mundo implícitas residem em tal designação? Que concepções diferentes poderiam inspirar outras compreensões possíveis daquilo que designo por "paisagem", e o que posso aprender com elas? Quais traços de uma "paisagem" me são invisíveis, ou que excluo, ao conceber e nomear de uma forma e não de outra? Nos estudos de letramento crítico, assim como nas reflexões de Jullien (2010, p. 204), a interação entre línguas e culturas é considerada extremamente produtiva, pois "ao introduzir uma exterioridade relativa, comparativa, do pensamento em relação à sua língua, esse confronto fazia-a reconhecer e medir a configuração do pensável na qual ela mesma se articulava".

Diante de "uma exterioridade relativa, comparativa": no diálogo produtivo com outras culturas, nossa cultura se vê obrigada a se repensar e pôr à prova suas próprias categorias, assumindo seu caráter de inacabamento. É isso que Jullien (2010, p. 202) propõe ao sugerir que o diálogo pode recolocar as culturas "no canteiro de obras vindouro de autorreflexão do bumano", capaz de romper com o "autorreflexo hoje planetariamente produzido pela uniformidade”. Resta saber em que língua se daria um diálogo entre culturas. Poderia-se adotar uma língua franca, tal como a língua inglesa? Seria viável, ou até mesmo justo, que uma única língua pudesse intermediar um diálogo entendido como "dia-logo", enquanto "plena 
exigência a um e a outro de seus componentes"? Como seria de se esperar, Jullien desaconselha a adoção de uma língua específica como o inglês, por exemplo. Se o diálogo acontece em apenas uma das línguas, sem que a outra língua também se faça ouvir, joga-se um jogo de cartas marcadas, com "dados viciados" (JULLIEN, 2010, p. 200). Sob o pretexto de mediar o debate, o inglês, por exemplo, acabaria trazendo seus próprios valores para um encontro intercultural, ditando as regras e condições para esse diálogo. Por isso, cada um dos participantes deve se engajar no diálogo em sua própria língua, porém traduzindo o outro. ${ }^{10}$ A tradução, segundo Jullien (2010, p. 200), "obriga, com efeito, a reelaborar o seio mesmo de sua própria língua, logo, a reconsiderar seus implícitos, para tornar esta disponível à eventualidade de um outro sentido”. Daí a crença do filósofo na tradução enquanto "a única ética possível" em um mundo globalizado um mundo onde é preciso resistir ao impulso uniformizante que, em nome de um pseudodesenvolvimento global e igualmente benéfico para todos, acaba por solapar as diferenças e calar as vozes destoantes. Trata-se de uma falácia, pois “assim como o nivelamento não é a igualdade, o 'standard' não é a paz” (JULLIEN, 2010, p. 203). É somente através do diálogo/ dia-logo que podemos resistir à uniformização que se impõe por meio de uma universalidade excludente, mantenedora de profundas desigualdades e injustiças sociais.

Para não perpetuar essas desigualdades ao favorecer apenas um dos lados do conflito, a língua inglesa não deve se constituir como língua franca, capaz de mediar de forma neutra ou desinteressada um diálogo entre culturas. Como sugerido por Jullien (2010), o diálogo não pode acontecer em uma única língua, que ameaça ditar as normas para o diálogo; cada cultura deve traduzir em sua própria língua os enunciados das outras. Qual seria então o papel da língua inglesa? Como uma das possíveis línguas nesse

\footnotetext{
${ }^{10}$ Posição análoga é a de Santos (2015), para quem a adoção de uma única língua como suporte para o processo tradutório é complicada por dois fatores: primeiro, dificilmente as duas ou mais culturas em situação de contato terão o mesmo domínio dessa língua, o que implicaria uma relação assimétrica de poder entre as culturas; segundo, no caso de situações de contato entre uma ex-potência colonial (como a Inglaterra), e uma ex-colônia (a Índia, por exemplo), o uso da língua inglesa como suporte para a tradução acarretaria uma "impronunciabilidade de algumas aspirações centrais dos saberes e práticas que foram oprimidos na zona colonial” (SANTOS, 2015, p. 134).
} 
diálogo, o inglês pode ser idealizado não como língua franca, ${ }^{11}$ mas enquanto uma lingua fraca, à maneira de Vattimo (2004).

Para o filósofo italiano, só é possível conceber uma sociedade democrática baseada em uma ontologia fraca, resultante do enfraquecimento dos valores ou estruturas sobre as quais assentava a Modernidade, tais como justiça, verdade ou progresso. Do mesmo modo como ainda precisamos de uma ontologia, mesmo que apenas para demonstrar o quanto está fadada à fragmentação (2004, p. 19), ainda precisamos falar em justiça, verdade e progresso, mas podemos utilizar esses conceitos enquanto verdades fracas, ou seja, relativas a um contexto social e histórico específico, sem a menor pretensão de universalidade ou abstração metafísica. Segundo Vattimo (2004), vivemos em uma época em que o próprio valor de verdade tem muito menos a ver com objetividade do que com a negociação, o consenso e a participação em ações compartilhadas. Daí a necessidade de buscarmos a solidariedade - e não a competitividade -, e a redução da violência de quaisquer tipos - e não a afirmação de princípios metafísicos ou modelos científicos de sociedade. Em tempos de verdades fracas, contingentes ou contextualmente situadas, sugere Vattimo (2004, p. 36, tradução nossa), cabe à filosofia a tarefa de buscar o sentido da história não em seu desenvolvimento quantitativo, mas na "intensificação generalizada do significado da existência". ${ }^{12}$

De modo semelhante, o inglês poderia se configurar como língua fraca em três aspectos: primeiro, por possibilitar o acesso inicial a uma série de discursos provenientes de diferentes países ou comunidades virtuais, de modo a colocar em contato duas ou mais culturas que passariam a se traduzir reciprocamente, cada uma em sua própria língua; segundo, como uma língua passível de apropriação por falantes de outras línguas, que nela inserem seus próprios sotaques e neologismos. Para muitos desses falantes, uma língua e uma identidade nacionais podem não ser tão fortes quanto outras formas de afiliação, como uma profissão, uma religião ou um hobby - nesse caso, a língua inglesa lhes permite transitar por diferentes espaços de identificação

\footnotetext{
${ }^{11}$ Uso o termo "língua franca" em seu sentido inicial e mais restrito; vale lembrar a existência de estudos mais atuais que propõem uma definição mais flexível do termo.

${ }^{12}$ No original: "a generalized intensification of the meaning of existence, implying solidarity rather than competition and the reduction of all forms of violence rather than the affirmation of metaphysical principles or the endorsement of scientific models of society".
} 
e aproveitar oportunidades profissionais e acadêmicas. Um terceiro aspecto do inglês como língua fraca diz respeito à precariedade da comunicação intercultural, marcada pela falta de garantias quanto à inteligibilidade mútua ${ }^{13}$ ou à comunicação bem sucedida, pautada na transparência dos significados. Nesse sentido, falar em inglês como língua fraca implica o reconhecimento da impossibilidade de uma língua franca, universal, capaz de representar ou expressar integralmente os anseios de diferentes povos. Como lembrou Jullien (2010), os valores culturais são inegociáveis, e não coincidem entre si - daí a necessidade de traduzir, abrindo-se ao modo de ser e de pensar do outro, e assim refletir-se criticamente a partir das diversas relações que se pode estabelecer com outrem. Essa reflexão constitui o mote dos trabalhos de letramento crítico já mencionados aqui. A forma como concebem a reflexão crítica da linguagem como prática social contextualizada, de modo a possibilitar uma abertura a outras leituras e interpretações possíveis para um mesmo texto, se assemelha à ideia de diálogo entre culturas através da tradução, elaborada por Jullien (2010), e sua importância para uma filosofia e uma ética contemporâneas. Para o filósofo francês, nossa primeira exigência ética, anterior a qualquer escolha ou determinação moral, reside em "tomar um recuo no espírito" e "reconsiderar os pressupostos sepultados, sedimentados", a partir dos quais pensamos e, com isso, encontrarmos uma iniciativa em nosso pensamento" (JULLIEN, 2010, p. 181). Segundo Jullien, é só assim que nos constituímos enquanto sujeitos, capazes então de participarmos de um diálogo inteligente entre culturas.

Não seria esse processo de tomada de recuo no espírito, e de reavaliação de pressupostos sedimentados, o próprio desenvolvimento de um letramento crítico, conforme a discussão realizada até aqui, apoiada em autores como Souza (2011a, 2011b)? Por acreditar ser possível responder afirmativamente a essa questão, entendo o desenvolvimento do letramento crítico de alunos e professores como um movimento de prospecção, tal como proposto por Jullien (2010), a partir de sua noção de defasagem entre culturas: um movimento que nos leva a "considerar um alhures", que

\footnotetext{
${ }^{13}$ Rajagopalan (2010) denuncia o caráter essencialmente político - e, portanto, ético - da noção de inteligibilidade. Para o linguista, as reflexões sobre as línguas ainda se acham presas a uma forma de pensar a linguagem característica do século XIX. Segundo o autor, é a disposição ou boa vontade por parte dos falantes em reconhecer uma língua comum que garante a inteligibilidade, e não um conjunto de características linguísticas estáveis ou generalizáveis.
} 
"explora até onde outros caminhos podem ser trilhados", estimulando "o trabalho inventivo do pensamento" (JULLIEN, 2010, p.185), de forma a sermos capazes de reconhecer uma série de modos de existir e de pensar diferentes do nosso, e assim nos relacionarmos eticamente com as diferenças.

$\mathrm{Na}$ convivência com essas diferenças, o conflito será inevitável. Como lidar com ele, e qual postura adotar diante da alteridade? Freire (apud SOUZA, 2011a, 2011b) lembra que, em qualquer situação de encontro com o outro, trazemos os esquemas interpretativos que nos constituem. Com isso, inconsciente ou inadvertidamente, ouvimos as palavras do outro com a disposição de atribuir-lhes sentidos conforme nossos próprios sistemas de valores, crenças e ideologias. Desse modo, corre-se o risco de ignorar tudo aquilo que é diferente de nossos esquemas conceituais, e de acreditar que nossa visão de mundo e nossos conhecimentos são universais - o que nos torna incapazes de aceitar ou até reconhecer a existência de pontos de vista ou de valores diversos dos nossos. Daí a importância, enfatizada por Freire, e já mencionada anteriormente, de um exame crítico de nossas próprias posturas e crenças em relação ao outro, em situações de conflito epistemológico - "ler se lendo", conforme já sugerido por Souza (2011a, 2011b).

É no sentido de desenvolver essa postura ética perante o outro preservando sua integridade cultural sem incorporá-lo a um esquema conceitual pré-estabelecido e fechado a novas possibilidades de significação - que o ensino de língua inglesa pautado em uma proposta de letramento crítico pode fazer a diferença, contribuindo para uma ampliação de nossas maneiras de compreender o mundo. Nessa perspectiva, o estudo de um texto em língua inglesa a respeito dos costumes e tradições de outros países pode, por exemplo, levar professores e alunos a uma reflexão crítica sobre como nossas leituras são influenciadas por determinados estereótipos, sobre como esses estereótipos são construídos e nos impedem de apreender interpretações diferentes. Por fim, poder-se-ia chegar à constatação da necessidade de uma atitude mais ética perante o estrangeiro, sem tentar reduzi-lo a uma única representação possível, de acordo com nossos esquemas conceituais.

Para traduzirmos e nos engajarmos em um diálogo inteligente com outras culturas, o conhecimento sistêmico de uma língua estrangeira é importante, mas também é preciso ter em mente que ele se refere à língua como um sistema abstrato, descontextualizado, e que em diferentes situações de uso, por falantes situados em diversos contextos socioculturais, pode 
desempenhar um papel mais ou menos decisivo. Um aluno de universidade brasileira interessado em fazer uma prova de proficiência em inglês para estudar fora do país, por exemplo, tem necessidades comunicativas de uso da língua diferentes das de uma participante de jogos de navegador on-line em massa, ou de interpretação de personagem on-line, interagindo simultaneamente com outros jogadores de países diferentes, cuja língua materna pode ou não ser a inglesa. Enquanto o primeiro necessitará, entre outras coisas, dominar gêneros acadêmicos escritos e ter bom conhecimento de gramática, a segunda precisará negociar sentidos com falantes de diferentes países, sem necessariamente ser proficiente na língua. Para o primeiro, um bom conhecimento de vocabulário pode ser indispensável, enquanto a segunda pode aproveitar a multimodalidade do ambiente virtual on-line para decodificar ou codificar sentidos em língua inglesa.

Não é difícil imaginar uma jogadora de videogames frequentando o mesmo curso de inglês que um estudante universitário interessado em estudar fora. Nesse caso, o professor que se identifica com o letramento crítico vai se mostrar sensível às diferentes expectativas e necessidades comunicativas de cada um desses alunos, planejando suas aulas conforme os possíveis contextos e situações de uso da língua inglesa por parte dos alunos. A seleção do que e como ensinar - quais aspectos do conhecimento sistêmico da língua a ensinar - pode ser orientada por esses contextos e situações. ${ }^{14}$

Ao conhecimento de regras e convenções da língua Canagarajah (2014) atribui o nome de conhecimento proposicional. Em tempos de globalização, em que a diversidade de falantes e de contextos e situações de uso da língua aumenta vertiginosamente, esse conhecimento se torna cada vez mais insuficiente para que os falantes utilizem a língua para a comunicação intercultural. Por isso, argumenta o autor, é preciso valorizar o que chama de conhecimento procedimental, que consiste no conhecimento de estratégias de negociação do sentido; ou o conhecimento de como negociar, ou de "como se virar" na língua inglesa.

\footnotetext{
${ }^{14}$ Em uma entrevista concedida ao autor (HASHIGUTI; TAGATA, 2016), Souza sugere que uma atitude ética do professor de línguas começa com o reconhecimento das variantes sociais que caracterizam a língua em seu uso concreto em situações específicas. A partir daí o professor pode sensibilizar seus alunos para os usos da língua em diferentes contextos e situações, cada uma das quais com suas próprias regras ou convenções. Para Souza (2011a; 2011b), a ética é sempre fruto de ações e contextos históricos específicos, e varia de um contexto para outro, jamais constituindo uma essência.
} 
Para Canagarajah (2014), é esse conhecimento procedimental, e não o proposicional, que deve ser o foco principal do ensino de língua inglesa na contemporaneidade. Para o autor, foi-se o tempo em que o inglês era tido como uma língua homogênea, representada pela norma do falante nativo, que se desdobrava em um número específico de variações, como o inglês americano ou o britânico; foi-se também o tempo em que se acreditava que os alunos deviam aprender uma dessas variações. Em tempos atuais de globalização, sugere o autor, nossas interações em inglês com falantes de outros países e línguas são absolutamente imprevisíveis, pois a diversidade de padrões é muito superior às variações supostamente conhecidas. Atualmente, os falantes adaptam a língua inglesa aos interesses, valores e níveis de proficiência em cada interação. Por isso, "não é a nossa proficiência gramatical, mas nossa habilidade em negociar a diversidade de gramáticas em cada interação específica que possibilita o sucesso comunicativo" 15 (CANAGARAJAH, 2014, p. 769, tradução nossa). Nessa perspectiva, faz mais sentido falar em "práticas" do que em "variações", pois o termo implica uma norma padrão, cada vez menos observável no cenário da comunicação global, onde abundam possibilidades de interação em situações heterogêneas. Canagarajah (2014, p. 770) endossa a mudança paradigmática proposta pelo sociolinguista Jan Blommaert "de línguas imóveis para recursos móveis". Tratam-se de recursos que selecionamos de diversas línguas e outros sistemas semióticos de acordo com nossos propósitos comunicativos e o contexto social aos quais se prestam. Portanto, segundo Canagarajah (2014), para prepararmos os alunos para as práticas de letramento de que participarão, é preciso desenvolver-lhes não apenas o conhecimento proposicional - a gramática da língua - mas também, ou ainda mais, o conhecimento procedimental - as estratégias de negociação, a sensibilidade retórica e a conscientização linguística. Isso requer, de nossa parte, uma mudança pedagógica radical: de um foco no conhecimento para um foco nas práticas sociais concretas; e de um foco na cognição para um foco no contexto social.

A mudança pedagógica anunciada por Canagarajah parece se coadunar com a sugestão de ensino de língua inglesa na perspectiva do letramento crítico feita pelos teóricos mencionados neste trabalho. Primeiro, por sua concepção de língua não como estrutura, mas como uma "prática"

${ }^{15}$ No original: "it is not our grammatical proficiency, but our adeptness in negotiating the diversity of grammars in each specific interaction that enables communicative success". 
envolvendo falantes oriundos de diversos contextos e com propósitos comunicativos distintos, tendo a sua disposição uma série de recursos que utilizam de acordo com esses propósitos e com o contexto social. Segundo, ao levar em conta a possibilidade de uso da língua por falantes cientes de diferentes normas e convenções, Canagarajah valoriza sua capacidade de se adaptarem a cada contexto, utilizando a língua criativamente até mesmo em situações de maior restrição a sua participação - daí a importância das estratégias de negociação.

A falta de proficiência linguística não será um obstáculo para a pedagogia criativa - e, por que não, para uma pedagogia do letramento crítico - imaginada por Canagarajah, se, como professores, soubermos valorizar outros recursos que os alunos com baixa proficiência já possuem, como sua sensibilidade retórica ou sua consciência linguística desenvolvida em experiências de vida e de aprendizado fora da sala de aula. Embora o autor não fale explicitamente do tema, a ética é uma preocupação subjacente a sua proposta de mudança paradigmática de ensino de inglês como língua internacional; afinal, em tempos de globalização, marcados pela imprevisibilidade das situações de interação com outros falantes, a forma mais ética de preparar professores e alunos para o imprevisível é desenvolverlhes o conhecimento procedimental: "aprendendo novas variedades do inglês, novos gêneros de comunicação, e novas formas de negociar a diversidade linguística"16 (CANAGARAJAH, 2014, p. 783, tradução nossa). Como negociar com a diferença linguística e cultural do outro, e como se apropriar criativamente dos novos gêneros comunicacionais? Para o autor, o professor de língua inglesa deve estar mais atento a como seus alunos aprendem do que com o que eles aprendem. Somente dessa forma o professor poderá prepará-los para a imprevisibilidade das situações de comunicação mediada pela língua inglesa e para a incerteza da vida em tempos de trocas interculturais, saberes complexos e múltiplas possibilidades de identificação.

Por seu papel determinante no cenário global, a língua inglesa pode desempenhar um papel importante na mediação inicial entre culturas diferentes. Como sugerido por Jullien, e corroborado por Santos, a tradução é a única ética possível em nosso mundo globalizado. Por que traduzir? Porque o mundo enfrenta graves problemas sociais, ambientais, políticos e econômicos, muitos dos quais agravados pela globalização hegemônica,

\footnotetext{
${ }^{16}$ No original: "learning new varieties of English, new genres of communication, and new modes of negotiating language diversity".
} 
que os saberes conhecidos parecem incapazes de resolver. Daí a necessidade de ampliação dos saberes possíveis ou disponíveis, aos quais podemos ter acesso através da tradução. Como vimos, a tradução assim concebida deve se dar a partir da defasagem - e não diferença - entre as culturas, enquanto um movimento de prospeção que nos leve a explorar caminhos da ação e do pensamento humanos nunca explorados, de modo a sermos capazes de imaginar uma práxis fundada na equidade, na tolerância e na valorização das riquezas natural e epistemológica do planeta.

\section{Conclusão}

Vimos, logo no começo deste trabalho, como a questão da ética deve constituir um critério norteador na elaboração de pesquisas sobre a linguagem, de acordo com Fabricio (2008), Moita Lopes (2008), Pennycook (2001) e Rajagopalan (2013), entre outros linguistas aplicados. Isso se deve a uma visão, compartilhada por esses autores, de linguagem enquanto prática social e, assim, politica e ideologicamente comprometida. Esses autores se baseiam em uma noção relacional de ética, entendida não como um conjunto de prescrições, mas como "uma forma contingente de pensar e agir que está sempre implicada em relações sociais, culturais e políticas" (PENNYCOOK, 2001, p.137).

Por sua disposição em problematizar relações sociais, culturais e políticas em torno das práticas de letramento, os estudos de letramento crítico aqui apresentados, desenvolvidos por teóricos preocupados com os aspectos ético-políticos do processo educacional, constituem um subsídio importante para a formulação de uma práxis (FREIRE, 1987) caracterizada por relações sociais mais justas, atitudes mais éticas em relação a diferentes saberes e conhecimentos, e pelo respeito ao meio ambiente. Por isso, uma proposta de ensino de inglês em uma perspectiva de letramento crítico parece-me especialmente apropriada para orientar o desenvolvimento de uma ética contemporânea, dentro e fora da sala de aula. A meu ver, tal proposta pode conscientizar professores e alunos da necessidade de contextualização das práticas envolvendo a linguagem em suas diferentes modalidades. Essa conscientização formará a base da autorreflexividade apontada por Andreotti, segundo a qual somos instados a perscrutar as relações entre nossas crenças individuais e as histórias coletivas, social, cultural e historicamente contextualizadas, que nos condicionam, mas não nos determinam. 
Uma proposta de ensino de língua inglesa pautada no desenvolvimento dessa autorreflexividade crítica pode estimular um pensamento inventivo e prospectivo, tirando-nos da zona de conforto de nossas velhas referências linguísticas e culturais, e levando-nos a sondar até onde podem ir as singularidades de outras línguas e culturas, e como essas singularidades nos forçam a rever nossas categorias de pensamento - atitudes que considero éticas. Nessa proposta, a competência procedimental idealizada por Canagarajah desempenha importante papel ao nos capacitar para negociar com a diferença de outrem e lidar com a incerteza característica de qualquer situação de tradução cultural. O professor de inglês pode promover o diálogo entre a língua inglesa e outras línguas, de forma que cada uma possa abrir-se inteiramente às singularidades da outra e, nesse movimento, reavaliar seus pressupostos, traduzindo-se. A tradução é a única ética possível em um mundo marcado por intensas trocas interculturais um mundo que, como já apontado por Moita Lopes (2008), nos oferece a possibilidade de sair de nossa zona de conforto, experimentando outros modos de ser e de pensar para além da vida local, e refletindo criticamente sobre as certezas que apagam quem pensa diferentemente de nós. A língua inglesa pode nos levar para fora dessa zona. Para isso, o ensino de inglês na perspectiva do letramento crítico deve sublinhar a importância da ética nas relações humanas e promover uma reflexão sobre a defasagem entre as culturas, de forma a sermos capazes de ampliar nosso repertório de saberes e experiências sociais no mundo.

\section{Referências}

ANDREOTTI, V. O. Critical and transnational literacies in international development and global citizenship education. Sisyphus - Journal of Education, Lisboa, v. 2, n. 3, p. 32-50, 2014.

CANAGARAJAH, S. In search of a new paradigm for teaching English as an international language. Tesol Journal, Malden, v. 5, n. 4, p. 767-785, 2014.

COPE, B.; KALANTZIS, M. Literacies. Cambridge: Cambridge University Press, 2012. 464 p.

FABRÍCIO, B. F. Linguística Aplicada como espaço de "desaprendizagem": redescrições em curso. In: MOITA LOPES, L. P. (Org.). Por uma Linguística Aplicada indisciplinar. 2. ed. São Paulo: Parábola Editorial, 2008. p.45-66.

FOUCAULT, M. Ética, sexualidade, política. Tradução Elisa Monteiro, Inês Autran Dourado Barbosa. 2. ed. Rio de Janeiro: Forense Universitária, 2006. 392 p. 
FREIRE, P. A importância do ato de ler. São Paulo: Cortez, 1987. 104 p.

GREEN, B.; LANKSHEAR, C.; SNYDER, I. Teachers and technoliteracy: managing literacy, technology and learning in schools. Sydney: Allen \& Unwin, 2000. 178 p. HASHIGUTI, S. T.; TAGATA, W. M. Entrevista com Lynn Mário T. M. de Souza. In: . (Org.). Corpos, imagens e discursos hibridos. Campinas: Pontes Editores, 2016.

JANKS, H. The importance of critical literacy. English Teaching: Practice and Critique, Waikato, v. 11, n. 1, 2012. p. 150-163.

JULLIEN, F. O diálogo entre as culturas: do universal ao multiculturalismo. Tradução André Telles. Rio de Janeiro: Jorge Zahar, 2010. 221 p.

MARCONDES, D. Textos básicos de ética: de Platão a Foucault. Rio de Janeiro: Jorge Zahar, 2007.157 p.

MOITA LOPES, L. P. Linguística Aplicada e vida contemporânea: problematização dos construtos que têm orientado a pesquisa. In: . (Org.). Por uma Linguística Aplicada indisciplinar. 2. ed. São Paulo: Parábola Editorial, 2008. p. 85-108.

PENNYCOOK, A. Critical applied linguistics: a critical introduction. New York; London: Routledge, 2001. 224 p.

RAJAGOPALAN, K. Por uma linguística crítica: linguagem, identidade e a questão ética. São Paulo: Parábola Editorial, 2013. 143 p.

RAJAGOPALAN, K. The rigmarole of intelligibility in world English(es) - or, on making sense of it all or, if you like, making the very idea of intelligibility intelligible. Revista Letras \& Letras, Uberlândia, v. 26, n. 2, 2010. p. 477-492.

SANTOS, B. S. A gramática do tempo. Para uma nova cultura política. 3. ed. São Paulo: Cortez, 2015. 511 p.

SANTOS, B. S. Um Ocidente não ocidentalista? A filosofia à venda, a douta ignorância e a aposta de Pascal. In: SANTOS, B. S.; MENESES, M. P. (Org.). Epistemologias do Sul. 1. ed. São Paulo: Cortez, 2010. p. 519-562.

SOUZA, L. M. T. M. O professor de inglês e os letramentos no século XXI: métodos ou ética? In: JORDÃO, C. M.; MARTINEZ, J. Z.; HALU, R. C. (Org.). Formação "desformatada": práticas com professores de língua inglesa. Campinas: Pontes Editores, 2011a. p. 279-303.

SOUZA, L. M. T. M. Para uma redefinição de letramento crítico. In: MACIEL, R. F.; ARAÚJO, V. A. (Org.). Formação de professores de línguas: ampliando perspectivas. São Paulo: Paco, 2011b. p. 128-140.

VATTIMO, G. Nibilism and emancipation: ethics, politics \& law. New York; Chichester: Columbia University Press, 2004. 197 p.

Data de submissão: 16/8/2016. Data de aprovação: 29/11/2016. 
